\title{
¿Para quién escribimos?
}

Isabel Alicia Quintana / Universidad de Buenos Aires - Conicet / isaaquintana@gmail.com

\section{Resumen}

El dossier reúne artículos de algunos integrantes del Comité Científico de la revista El taco en la brea que reflexionan a partir de la pregunta: «¿Para quién escribimos?». Los ensayos plantean la relación tensa entre escritura y normativa institucional, las expectativas y desencuentro con la comunidad de pares, el desarrollo complejo de redes en los que circulan los textos y sus lectores, las modificaciones en la producción de textos debido al uso de nuevas tecnologías, los resultados imprevisibles a causa de la apropiación de ensayos críticos por parte de lectores no estrictamente académicos (universitaria).

Palabras clave: escritura $\cdot$ lectura $\cdot$ instituciones $\cdot$ crítica literaria y cultural $\cdot$ transferencia

\section{Abstract}

This selection includes articles written by members of the Scientific Board of the journal $E l$ taco en la brea. They address thequestion of «For whom do we write?». The essays inquire the conflictive relation between writing and institutional norms, expectation and disagreement with the community of peers, the complex development of the webs through which texts and their readers circulate, the transformation in the production of texts because of the use of new technologies, and the unforeseeable results due to appropriation of critic essays by non strictly academic readers.

Key words: writing $\cdot$ readers $\cdot$ institutions $\bullet$ literary and cultural critique $\cdot$ transference

Hacia dónde va nuestra escritura. Esa pregunta merece, tal vez, otros dos interrogantes, ¿por qué? y ¿para qué escribimos? En el comienzo, ya que se trata de una escena de origen de la que todos alguna vez partimos, escribimos para alguien porque creemos que tenemos algo que decir respecto de la literatura y esperamos establecer algún tipo de diálogo real, virtual o imaginado con los lectores. De esa escena original parte tanto mi propia reflexión como algunos de los trabajos de este dossier. Esa escena se compone del recuerdo de tres instancias temporales fundamentales: los años de iniciación de lectura y escritura, los de formación en

Fecha de recepción: 15/08/2016 Fecha de aceptación: $30 / 08 / 2016$ 
el terreno académico y, finalmente, los de escritura profesional una vez instalados en el espacio institucional como docentes e investigadores.

En una vertiente proustiana, el origen de la escritura tiene un horizonte utópico inalcanzable que se retoma como imposibilidad en el presente. El ejercicio de escritura es una tarea en donde confluyen expectativas, demandas de los otros (la institución, las agendas académicas), políticas del mercado, transformaciones tecnológicas que impregnan nuestra práctica. La escritura siempre está ahí pero ya no como deseo, o, al menos, el deseo es absorbido por las demandas y prescripciones que el formato paper determina. En un punto el "para quién escribimos» se asoma como un fantasma porque por momentos parece que sólo escribimos o podemos escribir para esa voraz requisitoria institucional que evalúa nuestros trabajos de acuerdo a la cantidad de papers publicados, indexados, etc. Pero también, cuando realmente deseamos fervorosamente escribir porque un tema nos convoca y nuestras investigaciones avanzan y necesitan volcarse en trabajos para que otros los lean y discutan, la maquinaria burocrática aplicada a la cosificación de nuestro trabajo (siempre hay una planilla que completar, un informe que realizar, etc.) nos aleja de nuestra meta y aniquila nuestro deseo. La escritura deseante parece postergarse, se pierde en los vericuetos de un Yo volcado a una multiplicidad de tareas que postergan una y otra vez la verdadera escritura.

La propuesta del dossier: «¿Para quién escribimos?», queda en ese sentido también desplazada, ya que si nuestro propio deseo, escribir, se encuentra debilitado, aquello que parece como un horizonte utópico también comienza a resquebrajarse: escribimos porque eso es lo que queremos e imaginamos una comunidad de lectores que serían los receptores de nuestros trabajos pero nuestro objetivo se frustra.

Ahora bien, a pesar de todo, claro, seguimos escribiendo más allá de las condiciones de posibilidad de nuestra escritura. La persistencia significa que nuestro deseo permanece porque la literatura sigue existiendo, hasta plasmarse en un cuerpo, un corpus en el que se juegan nuestras pulsiones, lecturas, objetos de estudio y también, una suerte de comunidad imaginada que sería partícipe de esa experiencia.

La dirección es contraria a la del horizonte de expectativas de la teoría de la recepción, puesto que no dejamos de lado nuestras premisas para acercarnos a un supuesto lector, sino que el otro aparece como partícipe de nuestro propio universo, o, al menos, compartiendo un suelo de positividad que habilitaría el diálogo, el intercambio de ideas, o simplemente la lectura. Es decir, no renunciamos a nuestras ideas para ir al encuentro de nuestros lectores. Por el contrario, planteamos hipótesis, sostenemos argumentos, desarrollamos una crítica. En ese camino, la confrontación de ideas es una instancia que aparece como una de las consecuencias lógicas y también la apertura al diálogo. En ese sentido, la crítica inicia cada vez una instancia de reflexión o, al menos, así debería ocurrir. De manera más radical, la crítica tendría que poner en crisis un universo compartido de creencias: esa sería la postura puesta en práctica por Barthes y otros posestructuralistas, pero allí es donde parece que el Yo se siente amenazado y entonces la crí- 
tica transita por carriles más tranquilos huyendo al debate. Apelando brevemente a la tradición crítica en nuestro país podemos pensar en esos momentos que en coyunturas específicas se desarrollaron debates polémicos en torno a la relación entre literatura y sociedad. El siglo xx está plagado de debates que apuntaban a lectores específicos que, a su vez, respondían implacablemente desde posturas claramente definidas.

Tal vez, en el momento en que el universo de postulaciones fuertes del campo de la teoría y de la crítica comienza a mermar, es el momento en que emergen los giros (giro subjetivo, giro de la imagen, giro animal) habilitando a un tipo de lector con el que no se busca polemizar sino más bien mostrarle el cementerio de la crítica y la teoría, al menos del siglo pasado. Sin embargo, de esa crisis surge una crítica que se nutre de una teoría más basta marcando la ineludible relación entre arte y vida. Todo el campo de la biopolítica, los estudios sobre la imagen, la irrupción de otros soportes en el seno de la literatura confluyen a la pregunta planteada por la vanguardia: ¿qué es el arte?, que pensada desde nuestro quehacer supone pensar qué es la literatura y, en definitiva, para quién se escribe.

Dos cuestiones fundamentales para acercarnos a esta pregunta. En primer lugar, la coincidencia en varios de los trabajos del dossier que rescatan en la práctica de la escritura los lectores que se apropian de esos materiales: alumnos, docentes de nivel medio y terciario, participantes de talleres literarios, etc. Ese espacio, tan ajeno para algunos integrantes de nuestra comunidad, se revela como uno de los más activos a través del uso a veces no ortodoxo de los textos. Una comunidad lectora que pone a funcionar de otra manera las monografías escritas por los investigadores y docentes, y que se leen de modo insospechado por sus propios autores. Es más, incluso rescatando trabajos olvidados.

En segundo lugar, de Barthes a Rancière, estas formas de leer suponen un lector emancipado, incluso que trabaja a contrapelo de lo que los mismos textos formalizan como práctica de lectura. $Y$ es en ese sentido que la pregunta por el que: "¿para quién escribimos?» se torna incluso en un punto superflua. Porque en definitiva, no importa claramente para quién, sino de qué modo existe una circulación de los textos poco previsible que los convierte en lo impensado de la teoría y la crítica académica. 